
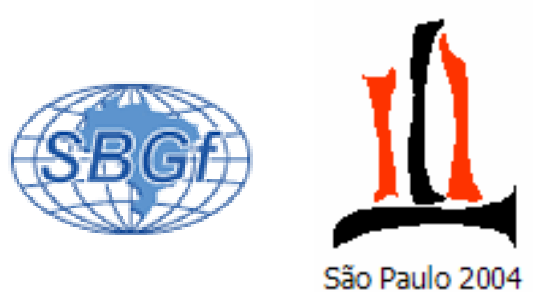

\title{
Apoio à Decisão em Obras de Implantação e Ampliação da Infraestrutura Aquaviária
}

Roberto Bianco

Instituto de Pesquisas Hidroviárias - INPH

Copyright 2004, SBGf - Sociedade Brasileira de Geofísica

Este texto foi preparado para a apresentação no I Simpósio de Geofísica da Sociedade Brasileira de Geofísica, São Paulo, 26-28 de setembro de 2004. Seu conteúdo foi revisado pela Comissão Tecno-científica do I SR-SBGf mas não conteúdo foi revisado pela Comissão Tecno-científica do I SR-SBGf mas não reprodução total ou parcial deste material para propósitos comerciais sem prévia autorização da SBGf.

\section{Resumo}

A crescente demanda de navios de grande porte aos terminais marítimos e fluviais brasileiros, vem ocasionando a necessidade de reestruturação das condições de acesso e das obras de acostagem a tal realidade. Neste contexto, as investigações, efetuadas em áreas de águas rasas, com a aplicação de métodos geofísicos, constituem-se em ferramenta ágil e poderosa, na orientação à tomada de decisões, seja na implantação ou na modernização da infraestrutura aquaviária já existente.

\section{Introdução}

A manutenção da infraestrutura aquaviária, no que concerne à conservação das profundidades existentes, está basicamente condicionada às taxas de assoreamento, ocorrentes em terminais marítimos e fluviais. Sabe-se que inúmeros portos brasileiros são permanentemente submetidos a processos de assoreamento, causados por sedimentos, quase sempre transportados de grandes distâncias, à montante dos rios, ou remobilizados por correntes de maré, tendendo a depositar-se em áreas de baixa energia hidrodinâmica, representadas pelas bacias de evolução e por eventuais trechos ao longo dos canais de navegação. Tal evento obriga a realização de dragagens de manutenção, cuja periodicidade deve ser planejada com base em monitoramentos batimétricos freqüentes. Por outro lado, projetos de ampliação ou implantação da infraestrutura aquaviária, normalmente por se originarem da necessidade em reestruturar as condições de acesso e de acostagem para navios de maior porte e calado - que têm demandado, cada vez mais, os terminais nacionais necessitam, além das informações de batimetria, também do uso integrado de técnicas, diretas e indiretas, de investigação de subsuperfície. Considerando que diversos portos e terminais brasileiros carecem, ainda no momento, de estudos básicos detalhados, que permitam a tomada de decisões, com segurança, o presente artigo tem a intenção de ressaltar, como de vital importância, a execução de tais estudos - incluindo-se a perfilagem sísmica contínua e sonar de varredura lateral -, sobretudo quando os objetivos visados passam a envolver obras de aprofundamento e expansão portuária. Muito já se falou da importância em dispor de informações precisas e confiáveis, com vistas ao desenvolvimento de projetos de ampliação da infraestrutura aquaviária. A definição de um projeto geométrico de canal de acesso, bacia de evolução e berços de atracação, associado ou não a projetos de sinalização náutica, está intimamente relacionada, entre outras, às características batimétricas, geológicas e geotécnicas do fundo marinho. A implantação de um projeto desses, seja em áreas virgens ou de ampliação da estrutura já existente, implicará, fatalmente, na realização, total ou parcial, de investimentos em obras de dragagem e derrocagem submarina, de aterros hidráulicos, de construção de molhes e enrocamentos, assim como de estruturas de acostagem, dentre outros. É neste momento, que as técnicas geofísicas podem ajudar, e muito, na consecução de tais projetos. A perfilagem sísmica contínua, preferencialmente complementada pelo uso do sonar de varredura lateral e da realização de sondagens mecânicas, tem sido uma das principais ferramentas de investigação indireta, com vistas ao reconhecimento e caracterização de subsuperfície, em áreas cobertas por água, principalmente pela relativa rapidez com que são executados os levantamentos de campo e processados os seus resultados.

\section{Metodologia}

A perfilagem sísmica contínua apoia-se no princípio da reflexão de ondas sonoras, utilizando contrastes de velocidade e densidade, existentes entre os diferentes meios atravessados. Como função de tais contrastes, reflexões da interface assim definida, são recebidas por sensores na superfície, que transmitem sinais préamplificados a um sistema de filtragem e amplificação final, sendo registrados digitalmente e/ou em papel eletro-sensível, conforme seus tempos de chegada. A figura 1, a seguir, ilustra a geometria utilizada nesta técnica.

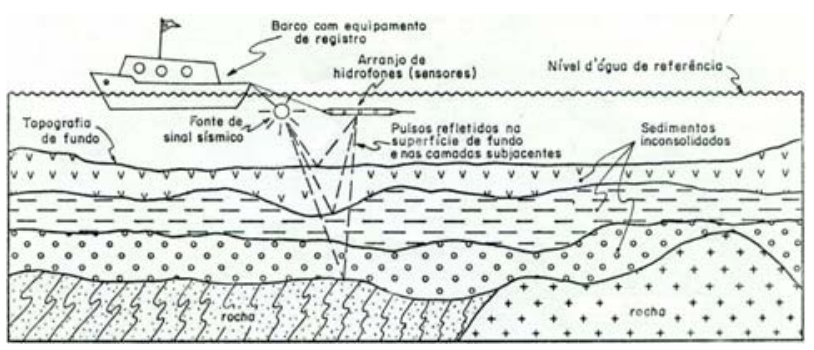

Figura 1: Geometria da técnica de perfilagem sísmica contínua (Souza, 1988).

Da mesma forma que a perfilagem sísmica, a técnica de sonografia também se apoia no princípio da reflexão de ondas acústicas, onde dois transdutores, submersos e dirigidos para ambos os lados da superfície de fundo, 
emitem sinais sonoros, em intervalos regulares de tempo. Estes transdutores atuam independentemente entre si, emitindo e recebendo sinais do fundo, que são gravados à medida que chegam ao registrador, e compondo uma imagem contínua da superfície investigada, que mostra padrões variáveis em função da rugosidade da superfície refletora, permitindo a caracterização litológica e estrutural do assoalho subaquático, e auxiliando na determinação da ocorrência, em área, de rochas submersas.

\section{Resultados}

A seguir, são descritos, de forma breve, alguns casos de obra, em que as técnicas de investigação geofísica estiveram à serviço de projetos de implantação ou ampliação portuária, com excelentes resultados.

\section{Caso 1: Porto de Aratu - BA}

Neste caso, o objetivo era a construção de um terminal marítimo, aliada a obras de dragagem e aterro hidráulico, para aprofundamento da via de acesso e criação de uma retroárea. Foram empreendidos serviços de topografia, batimetria, perfilagem sísmica e sondagens mecânicas a percussão e rotativas, complementados por ensaios geotécnicos de campo e de laboratório. Os resultados, analisados revelaram a presença de intercalações de rochas sedimentares brandas - folhelhos, siltitos, arenitos e calcários - em níveis de profundidade que interferiam no projeto de dragagem, auxiliando no dimensionamento do equipamento e na execução das obras. Abaixo, a figura 2 ilustra o caso relatado.

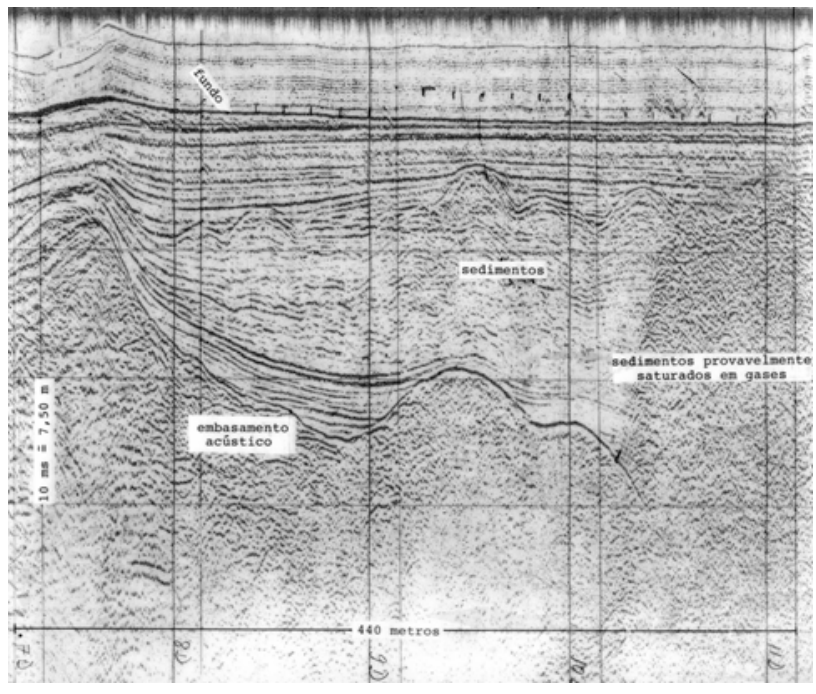

Figura 2: Rochas sedimentares brandas, representadas pelo embasamento acústico. Porto de Aratu - BA, 1983.

\section{Caso 2: Baía de Guanabara, Niterói - RJ}

Neste caso, o interesse foi definir projeto de dragagem e de obras de acostagem, visando a expansão de um terminal marítimo. Para isto foram executados serviços de perfilagem sísmica, complementados por sondagens jet-probe, que indicaram, na maior parte da área levantada, pouca interferência do embasamento acústico com as profundidades de projeto analisadas. A execução de sondagens a percussão foi recomendada, em função de alto-estruturais, existentes em alguns trechos, cuja natureza necessita ser confirmada, a fim de otimizar o projeto de aprofundamento. A seguir, as figuras 3 e 4 ilustram o caso relatado.

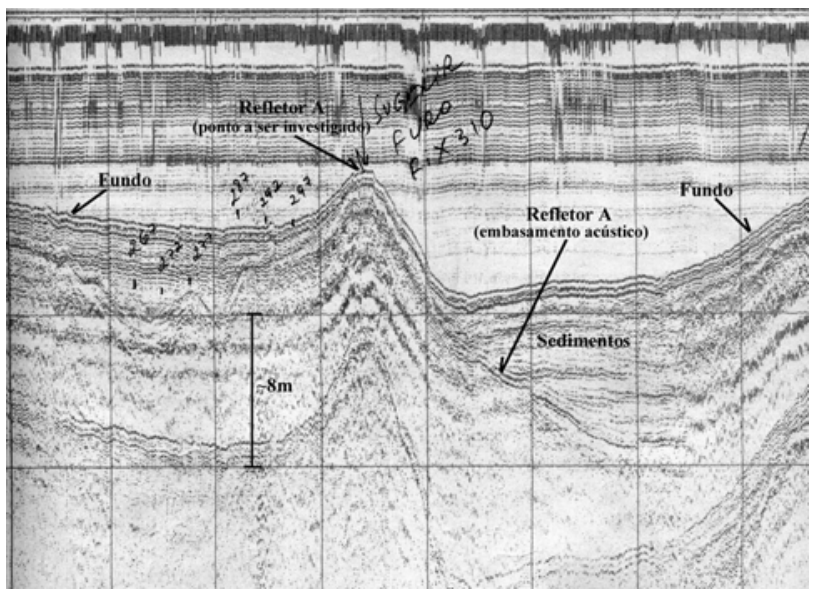

Figura 3: Sismograma mostrando alto do embasamento acústico, recomendando execução de sondagem a percussão. Baía de Guanabara, Niterói - RJ, 2004 (Fonte: MICROARS).

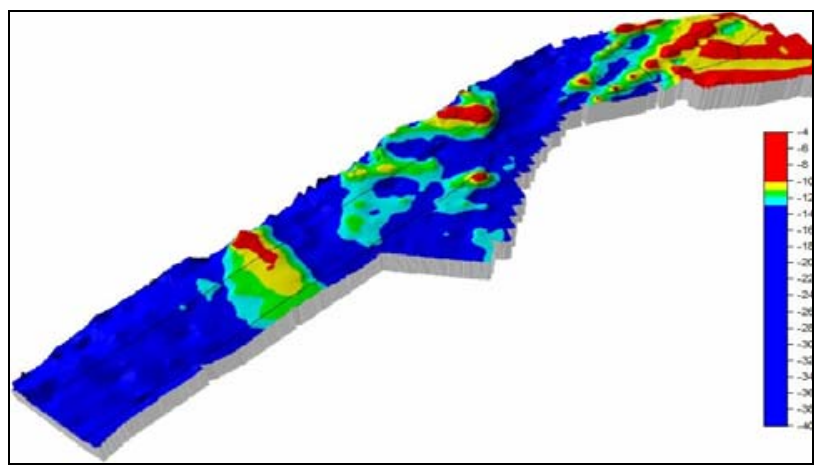

Figura 4: Modelo 3D baseado na interpretação de dados sismobatimétricos. Área azul, sem interferência com o embasamento acústico, e vermelha, indicando a necessidade de sondagens adicionais. Baía de Guanabara, Niterói - RJ, 2004 (Fonte:MICROARS).

\section{Caso 3: Porto de Paranaquá - PR}

Tendo como objetivo a eventual retirada de rochas próximas à bacia de evolução do porto, foram executados estudos com perfilagem sísmica contínua, sonar de varredura lateral e batimetria, numa área de rochas aflorantes no fundo estuarino. Os resultados obtidos, subsidiaram a realização de cálculos volumétricos de sedimentos e rochas, visando os respectivos projetos de dragagem e derrocagem submarina. A seguir, as figuras 5 e 6 ilustram o caso relatado. 


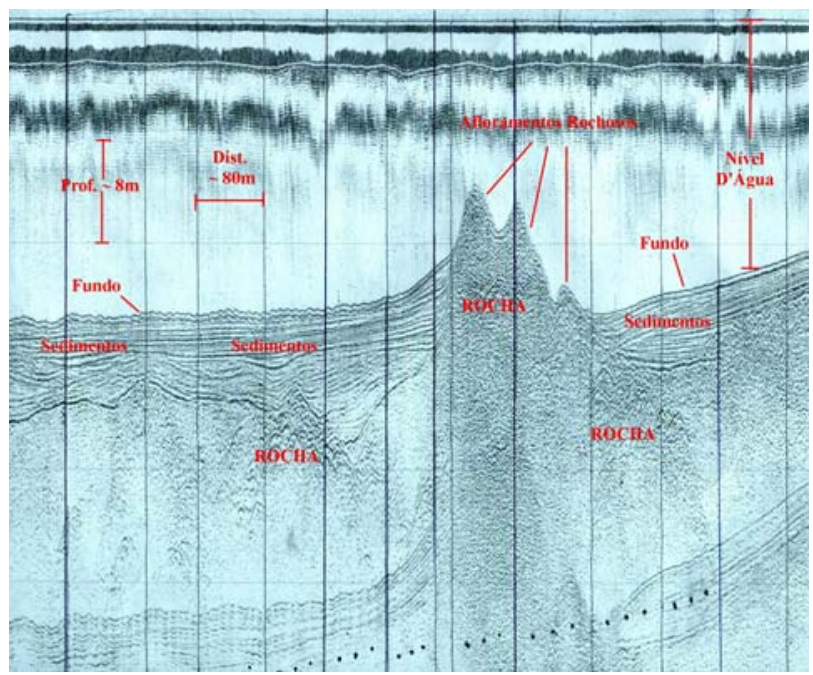

Figura 5: Registro sísmico obtido na região próxima ao Porto de Paranaguá - PR, 2002 (Fonte:MICROARS).

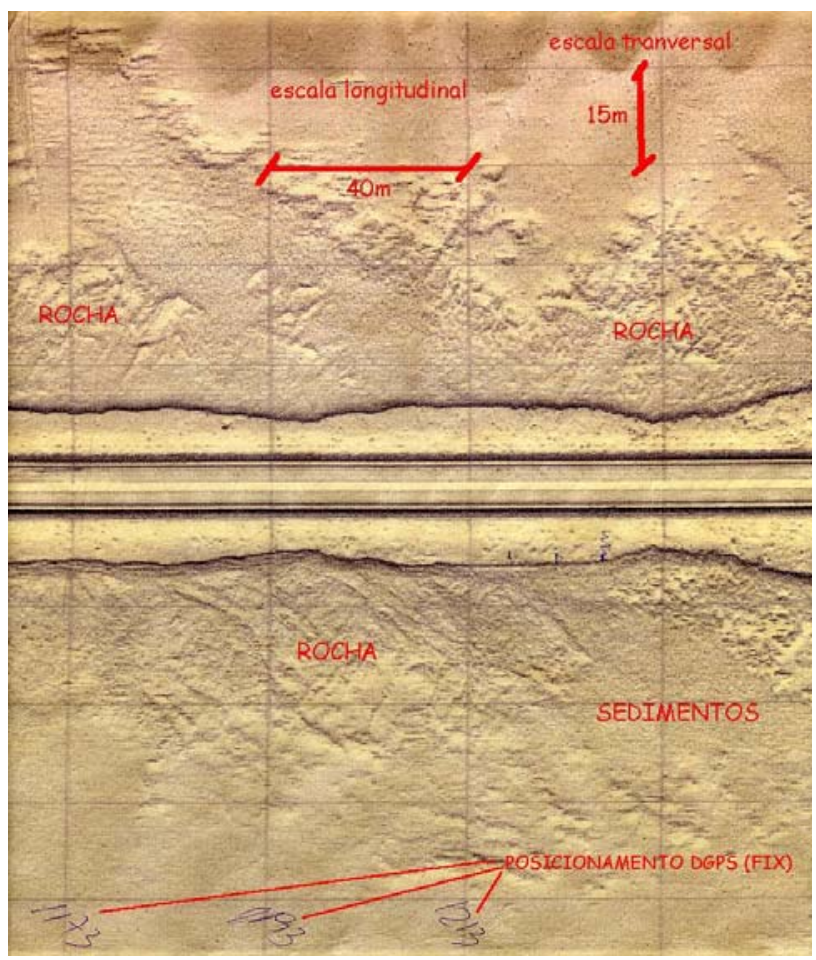

Figura 6: Sonograma obtido na região próxima ao Porto de Paranaguá - PR, 2002 (Fonte:MICROARS).

Na seqüência, a figura 7 apresenta uma visualização em modelagem 3D, elaborada com base na interpretação dos dados sísmicos, batimétricos e sonográficos levantados, e que serviu à elaboração dos cálculos de volume fornecidos. É importante observar o nível de detalhamento alcançado, na representação do modelo, somente possível, graças à integração das três técnicas geofísicas empregadas.

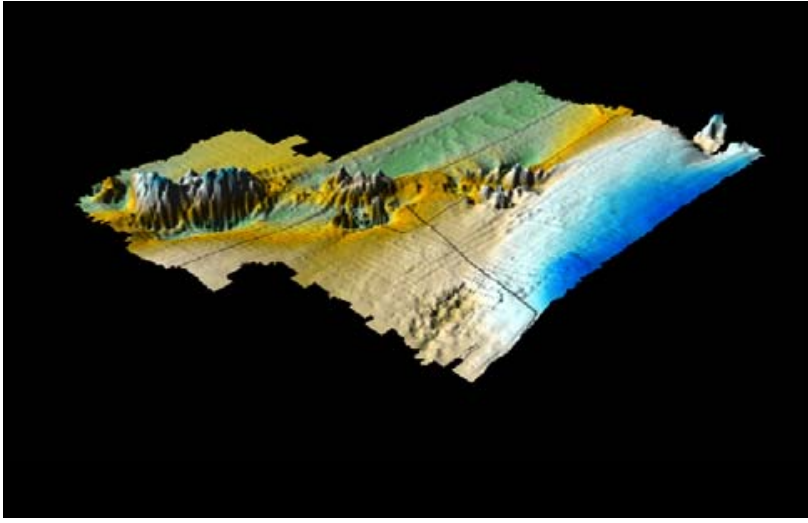

Figura 7: Modelo 3D baseado na interpretação integrada de dados sísmicos, batimétricos e sonográficos, obtidos em levantamento na região do Porto de Paranaguá - PR, 2002 (Fonte:MICROARS).

\section{Caso 4: Baía de Guanabara, Rio de Janeiro - RJ}

No presente caso, foram executados levantamentos sísmico e batimétrico, associados a sondagens a percussão em pontos restritos, com o intuito de subsidiar projeto de ampliação portuária. Embora a área de maior interesse tenha se beneficiado pouco com as informações obtidas - função da baixa resposta sísmica, no trecho coincidente com a incidência de profundidades muito reduzidas - mapeou-se, na área levantada, um notável paleocanal, soterrado por sedimentos essencialmente argilo-siltosos, muito moles a moles. A figura 8, a seguir, apresenta, traçado em linhas vermelhas, o paleocanal, mapeado com base nas interpretações dos registros sísmicos. A linha central tracejada, representa o respectivo talvegue, conforme observado nos sismogramas. De margem a margem, o paleocanal possui uma largura média aproximada, da ordem de 30 metros, confirmando dados da literatura consultada.

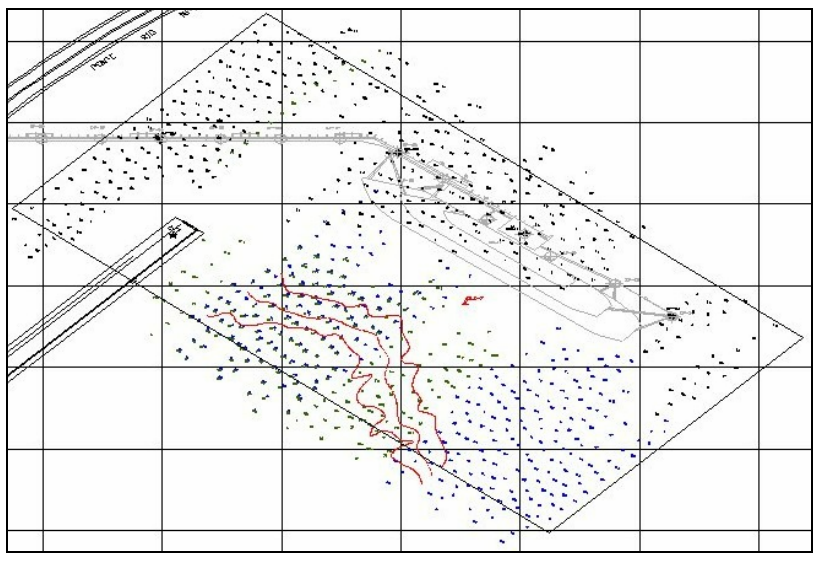

Figura 8: Representação, em vermelho, das margens e talvegue do paleocanal, conforme interpretação extraída de registros sísmicos. Baía de Guanabara, Rio de Janeiro - RJ, 2003 (Fonte:MICROARS). 
Tal fato, além de subsidiar futuras dragagens, principalmente no que concerne à natural instabilidade dos taludes, no decorrer da remoção desses sedimentos, é informação valiosa para eventuais projetos de fundação e o conseqüente dimensionamento do comprimento de estacas. A seguir, são apresentadas as figuras 9 e 10, mostrando, respectivamente, a informação bruta e interpretada, de um mesmo registro sísmico, onde é facilmente identificável o paleocanal mencionado no caso em tela.

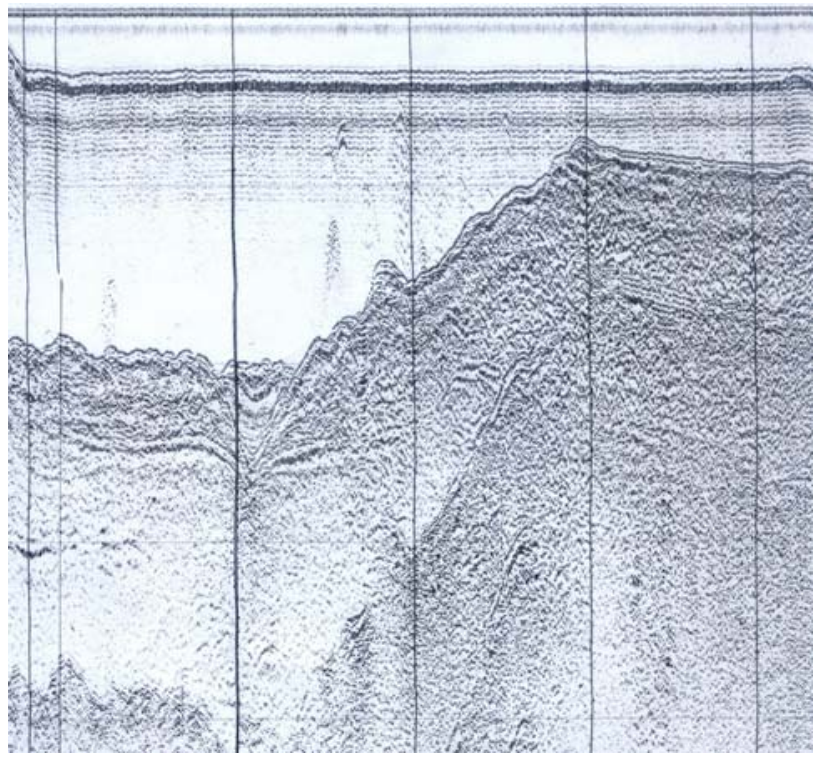

Figura 9: Registro bruto, obtido na região da Baía de Guanabara, Rio de Janeiro - RJ, 2003 (Fonte: MICROARS).

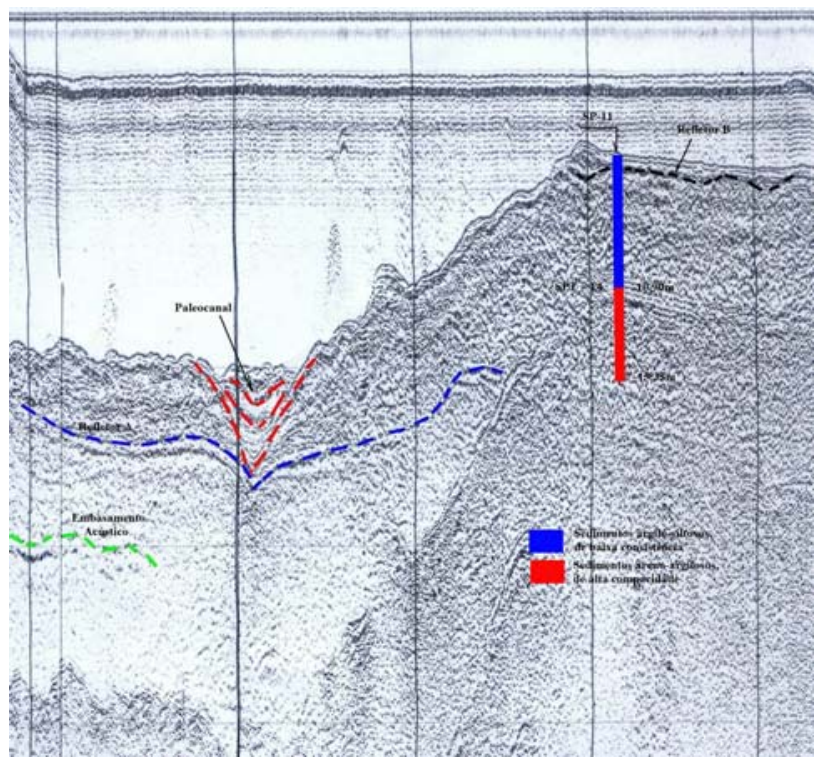

Figura 10: O mesmo registro da figura anterior, mostrando a interpretação adotada. Baía de Guanabara, Rio de Janeiro - RJ, 2003 (Fonte: MICROARS).

\section{Considerações Finais}

O estudo em áreas subaquáticas costeiras ou fluviais, notadamente as que estão sob a influência de terminais aquaviários, é grandemente facilitado pelo uso das ferramentas geofísicas de ecobatimetria, perfilagem sísmica contínua e sonografia, por envolverem "situações em que são importantes o tempo de obtenção dos resultados, o baixo custo operacional e uma alta resolução dos dados (até 1 metro na sísmica de reflexão e sonografia e até $20 \mathrm{~cm}$ na batimetria de precisão)" (GALLEA, SOUZA \& BIANCO, 1989). Técnicas de investigação direta, como as sondagens mecânicas a percussão e rotativas, embora desejáveis e mesmo fundamentais, muitas das vezes são relegadas, por serem de execução relativamente demorada e onerosa, o que costuma levar à redução da quantidade de furos, inicialmente programada. Por outro lado, considerando a natureza pontual da informação que oferece, é sempre arriscado inferir, para uma grande área não coberta pela investigação direta, a estratigrafia de subsuperfície, observada na vertical das sondagens executadas em menor número do que seria recomendável. Assim, as metodologias geofísicas tornam-se de grande utilidade, não apenas pelas questões relativas a prazo e custo, mas, sobretudo porque, através da interpretação das diferentes interfaces acústicas, presentes nos perfis sísmicos, é possível perceber-se a continuidade lateral e a morfologia das camadas litológicas, registradas nos boletins de sondagem, facilitando a otimização dos recursos implementados na pesquisa e o adequado apoio à decisão de projetistas, executivos e empreendedores, nas fases de planejamento e realização de obras de infraestrutura aquaviária.

\section{Agradecimentos}

Ao Instituto de Pesquisas Hidroviárias - INPH, pela oportunidade em escrever este artigo, e à MICROARS Consultoria e Projetos Ltda., pela gentileza em ceder os exemplos, aqui utilizados.

\section{Referências}

AMADOR, E. S., 1997. Baía de Guanabara e Ecossistemas Periféricos: Homem e Natureza, Edição do autor, 539 pgs., Rio de Janeiro (RJ).

BIANCO, R., SOUZA, L. A. P. \& CUNHA, A. G. N., 2003. Sísmica rasa e sonar de varredura lateral aplicados a projetos de dragagem e derrocagem submarina. $8^{\text {th }}$ International Congress of the Brazilian Geophysical Society, Rio de Janeiro (RJ).

GALLEA, C. G., SOUZA, L. A. P. \& BIANCO, R., 1989. A geofísica marinha de alta resolução: características e aplicações. In: II Congresso da Sociedade Brasileira de Geofísica, Rio de Janeiro (RJ), Boletim de Resumos, 176-197. 
SOUZA, L. A. P., 1988. As técnicas geofísicas de sísmica de reflexão de alta resolução e sonografia aplicadas ao estudo de aspectos geológicos e geotécnicos em áreas submersas. In: Congresso Brasileiro de Geologia, 35, Belém, POA, SBG, V.4, 1551-1564.

SOUZA, L. A. P., 1998. Exemplos de utilização de métodos geofísicos na investigação de áreas submersas. II Encontro Regional de Geotecnia e Meio Ambiente / II Workshop de Geofísica Aplicada, Rio Claro (SP), 19-20. CD ROM.

SOUZA, L. A. P., BIANCO, R. \& CUNHA, A. G. N., 2003. Sonar de varredura lateral: Um exemplo de aplicação no estudo de áreas de implantação de dutos submarinos. $8^{\text {th }}$ International Congress of the Brazilian Geophysical Society, Rio de Janeiro (RJ).

SOUZA, L. A. P., CAMPAGNOLI, F. \& GARCIA, F. C. V., 1999. Geofísica aplicada ao estudo de portos e rotas de navegação. 6 ${ }^{0}$ Congresso Internacional da Sociedade Brasileira de Geofísica, Rio de Janeiro (RJ).

SOUZA, L. A. P., SILVA, R. F. \& IYOMASA, W. S., 1998. Métodos de Investigação. In: Oliveira, A. M. S. \& Brito, S. M. A. (Eds.). Geologia de Engenharia, São Paulo (SP), ABGE, Cap. 11, Publicação IPT 2551. 